\title{
Mapping the current and future distributions of Onosma species endemic to Iran
}

\author{
Farzaneh KHAJOEI NASAB $^{1}$, Ahmadreza MEHRABIAN ${ }^{1 *}$, Hossein MOSTAFAVI ${ }^{2}$ \\ ${ }^{1}$ Department of Plant Sciences and Biotechnology, Faculty of Life Sciences and Biotechnology, Shahid Beheshti University, \\ Tehran 1983969411, Iran; \\ ${ }^{2}$ Department of Biodiversity and Ecosystems Management, Environmental Sciences Research Institute, Shahid Beheshti \\ University, Tehran 1983969411, Iran
}

\begin{abstract}
Climate change may cause shifts in the natural range of species especially for those that are geographically restricted and/or endemic species. In this study, the spatial distribution of five endemic and threatened species belonging to the genus Onosma (including O. asperrima, O. bisotunensis, O. kotschyi, O. platyphylla, and O. straussii) was investigated under present and future climate change scenarios: RCP2.6 (RCP, representative concentration pathway; optimistic scenario) and RCP8.5 (pessimistic scenario) for the years 2050 and 2080 in Iran. Analysis was conducted using the maximum entropy (MaxEnt) model to provide a basis for the protection and conservation of these species. Seven environmental variables including aspect, depth of soil, silt content, slope, annual precipitation, minimum temperature of the coldest month, and annual temperature range were used as main predictors in this study. The model output for the potential habitat suitability of the studied species showed acceptable performance for all species (i.e., the area under the curve (AUC) $>0.800)$. According to the models generated by MaxEnt, the potential current patterns of the species were consistent with the observed areas of distributions. The projected climate maps under optimistic and pessimistic scenarios (RCP2.6 and RCP8.5, respectively) of 2050 and 2080 resulted in reductions and expansions as well as positive range changes for all species in comparison to their current predicted distributions. Among all species, O. bisotunensis showed the most significant and highest increase under the pessimistic scenario of 2050 and 2080. Finally, the results of this study revealed that the studied plant species have shown an acute adaptability to environmental changes. The results can provide useful information to managers to apply appropriate strategies for the management and conservation of these valuable Iranian medicinal and threatened plant species in the future.
\end{abstract}

Keywords: climate change; endemic plant; MaxEnt; species distribution modeling; RCP2.6; RCP8.5; Iran

Citation: Farzaneh KHAJOEI NASAB, Ahmadreza MEHRABIAN, Hossein MOSTAFAVI. 2020. Mapping the current and future distributions of Onosma species endemic to Iran. Journal of Arid Land, 12(6): 1031-1045. https://doi.org/10.1007/s40333-020-0080-z

\section{Introduction}

Anthropogenic activities have increased greenhouse gases in the atmosphere and have been causing climate change most especially since the mid-20 ${ }^{\text {th }}$ century (Sala et al., 2000; Pereira et al., 2010; Peñuelas et al., 2013). Global warming affects all levels of biodiversity from individuals to ecosystems (Parmesan, 2006; Bellard et al., 2012). The most important effects are increases of

\footnotetext{
*Corresponding author: Ahmadreza MEHRABIAN (E-mail: a_mehrabian@sbu.ac.ir)

Received 2020-01-16; revised 2020-09-06; accepted 2020-10-03

(C) Xinjiang Institute of Ecology and Geography, Chinese Academy of Sciences, Science Press and Springer-Verlag GmbH Germany, part of Springer Nature 2020
} 
global temperatures, variations in the lifecycles of plants and animals, changes in the species distribution, loss of biodiversity, drought, wildfires, and others (Amedie, 2013). The geographic distribution pattern of species depends on many environmental variables and the ability of individual species to adapt to the new conditions. Climate change is one of the most important factors known to alter species distributions by reducing or expanding their geographical range (Tallis et al., 2008; Garcia et al., 2014; Alamgir et al., 2015). The Intergovernmental Panel on Climate Change (IPCC) estimates a high risk of extinction for plant species in the $21^{\text {st }}$ century and further projects that about 58\% of plants will lose their ecological niche and natural habitats to climate change in 2080 (Warren et al., 2013). Understanding the current and future spatial response patterns of plant species to climate change is a basic issue in ecology and conservation biogeography (Guisan et al., 2013; Guillera-Arroita et al., 2015).

Iran with more than 8100 vascular plant species has a diverse flora among the countries of southwestern Asia (Noroozi et al., 2016). A wide array of climatic conditions and pedological diversity have led to a high level of species richness in Iran (Hedge and Wendelbo, 1978) and approximately $24 \%-30 \%$ of Iranian vascular plants species are endemics (Akhani, 2006; Noroozi et al., 2016). Over the past decades, however, land use changes, overgrazing, overharvesting, as well as invasive and newly-introduced species have been threatening the plant diversity (Mehrabian, 2015; Sayadi and Mehrabian, 2016; Noroozi et al., 2018; Mehrabian et al., 2020a). Further, it is expected that climate change will have an additional impact on this extensive diversity (Parmesan, 2006; Loarie et al., 2008; Abdelaal et al., 2019) as it is estimated that if the $\mathrm{CO}_{2}$ concentration doubles by the year 2100, the average temperature in Iran will increase by $1.5^{\circ} \mathrm{C}-4.5^{\circ} \mathrm{C}$ (Roshan et al., 2011).

As endemic species are restricted to a specific geographic area and have unique genetic reserves (Bonn et al., 2002; Fois et al., 2018; Abdelaal et al., 2019), climate change may cause shifts in the natural range of those species unable to adapt to new climatic conditions and consequently may face a higher risk of endangerment or even extinction (Loarie et al., 2008; Abdelaal et al., 2019; Bender et al., 2019). The genus Onosma is one of the most important genera of Boraginaceae in Iran as it is comprised of a large number of species and has a high rate of endemism. So far, 54 species of this genus have been reported in Iran, 24 of which are endemic to the flora of Iran (Khatamsaz, 2002; Mehrabian and Amini, 2018). Moreover, this genus has medicinal properties and the root of its plants contain a major active chemical component known as shikonin (Sut et al., 2017). Shikonin derivatives have antibacterial, anti-inflammatory, and anti-tumor properties, and could bypass cancer drug resistance (He, 2009; Liu et al., 2010; Noula et al., 2010).

The limited distribution of endemic and rare species of this valuable genus as well as destructive human activities and droughts in recent years, have caused such severe damage to so many species that about 50\% are now found on the International Union of Conservation of Nature's (IUCN) Red List of Threatened Species (Mehrabian, 2015). The mounting destruction motivates us to investigate the repercussions of climate change on the future spatial distributions of endemic and threatened species of this genus, including O. asperrima Bornm (NT, near threatened), O. bisotunensis Attar (EN, endangered), O. kotschyi Boiss. (NT), O. platyphylla H. Riedl (NT), and O. straussii (Riedl) Khat. (NT) (Fig. 1). Climate change may negatively intensify the severity of the impact on the survival of these species. It is also critical to define the areas that these species with narrow niches inhabit or most likely inhabit in order to apply an appropriate strategy for their conservation (Dubuis et al., 2011; Kaky and Gilbert, 2016).

In this regard, species distribution modeling (SDM) has become a key method in ecology and conservation biogeography to predict the distribution of a species across geographic space and time using environmental data (Margules and Pressey, 2000; Groves et al., 2002; Graham et al., 2004; Peterson and Soberón, 2012). Numerous algorithms using presence and/or absence data have been developed to predict the geographical distribution of a given species (Soberón and Peterson, 2005; Elith et al., 2006; Elith and Leathwick, 2007, 2009). The maximum entropy (MaxEnt) modeling, however, is a machine learning algorithm that has been used extensively for distribution modeling since it is recognized as one of the best performing methods for modeling 
species presence-only data (Elith et al., 2006). MaxEnt is also recognized as a high-performance algorithm for predicting species distributions with few occurrence presence points as endemic species generally have low distributions (Elith et al., 2006; Phillips et al., 2006). Many ecological studies have used the SDM approach throughout the world (Rödder and Weinsheimer, 2009; Aragón et al., 2010; Rubidge et al., 2011; Khanum et al., 2013; Kujala et al., 2013; Legault et al., 2013; Adams-Hosking et al., 2015; Bleyhl et al., 2015; Luo et al., 2015; Sen et al., 2016; Ulrey et al., 2016). Despite the very rich species diversity in Iran, however, there have been very few studies in this field regarding local flora (e.g., Ardestani et al., 2015; Mazangi et al., 2016; Abolmaali et al., 2018). Hence, the objective of our study is to predict the current and future spatial distributions of O. asperrima, O. bisotunensis, O. kotschyi, O. platyphylla, and O. straussii for the first time to forecast the enlargement and direction of niche shifts in scenarios projecting climate change (RCP2.6 (RCP, representative concentration pathway) and RCP8.5) for the years 2050 and 2080 using a set of environmental variables and the MaxEnt model.
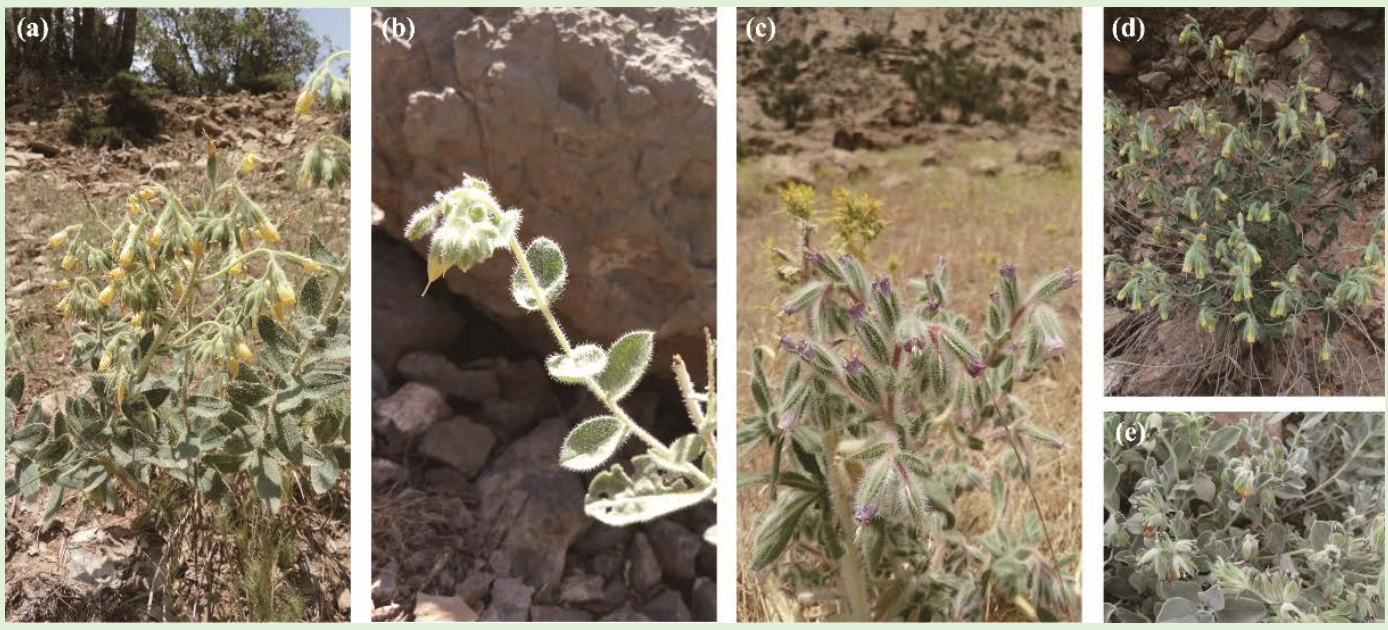

Fig. 1 Photographs of O. Asperrima (a), O. Platyphylla (b), O. Straussii (c), O. Kotschyi (d), and O. Bisotunensis (e) in Iran

\section{Materials and methods}

\subsection{Study area}

The study was conducted in Iran, and this country consists of the vast Iranian Plateau and has an area of about $1.65 \times 10^{6} \mathrm{~km}^{2}$. As the second largest country in the Middle East, Iran is located in the dry belt of Asia. It shares borders with Armenia and the Republic of Azerbaijan in the northwest, the Caspian Sea in the north, Turkmenistan in the northeast, Afghanistan and Pakistan in the east, Turkey and Iraq in the west, and the Persian Gulf and the Gulf of Oman in the south. Climatic factors heavily influence the distribution patterns of plant taxa, while other ecological factors have more localized effects (Zahran, 2010). Orogenic massifs surround the central plateau of Iran and act as a natural barrier to the penetration of humidity to these zones. This also shapes the diverse rainfall patterns. Iran is one of the most mountainous countries in the world. Its landscape is surrounded by several high, rugged mountain ranges such as the Caucasus, Zagros, Alborz, and Kopet-Dagh. The Zagros system has a northwest-southeast orientation extending from eastern Turkey to southwestern Iran (Fisher, 1968). It forms a wall among the Iranian Plateau, the Mesopotamian, and the Persian Gulf. It has a mean elevation of $1200 \mathrm{~m}$ a.s.l. and the highest peak, Zard Kuh, reaches $4231 \mathrm{~m}$ a.s.l. (Homke et al., 2004). The study covers the Mediterranean macro-bioclimate (Rivas-Martínez et al., 1997, 1999).

\subsection{Species occurrence data}

We have selected five species (O. asperrima, O. bisotunensis, O. kotschyi, O. platyphylla, and $O$. 
straussii) of Onosma genus because enough data were available for modeling. Distributional data on characterizing species were gathered from (i) field surveys during 2009-2017; (ii) literature records available in Flora Iranica (Riedl, 1967) and Flora of Iran (Khatamsaz, 2002); and (iii) historical data available in the herbaria of HSBU, IRAN, TARI, WU, BASU, and B (the herbarium acronyms follow the study of Thiers (2019)). Due to the lack of careful and reliable absence species distribution data, only presence data were used in this study. Distribution map (presence data) of O. asperrima, O. bisotunensis, O. kotschyi, O. platyphylla, and O. straussii in Iran is shown in Figure 2. The point inputs to the models developed in this study were collected from their habitats in the west and southwest of Iran such as Fars, Lorestan, Kurdistan, Khuzestan, Kermanshah, Hamedan, Markazi, Ilam, and Kohgiluyeh and Boyer-Ahmad provinces and certain areas in the south and central provinces like Kerman and Isfahan.

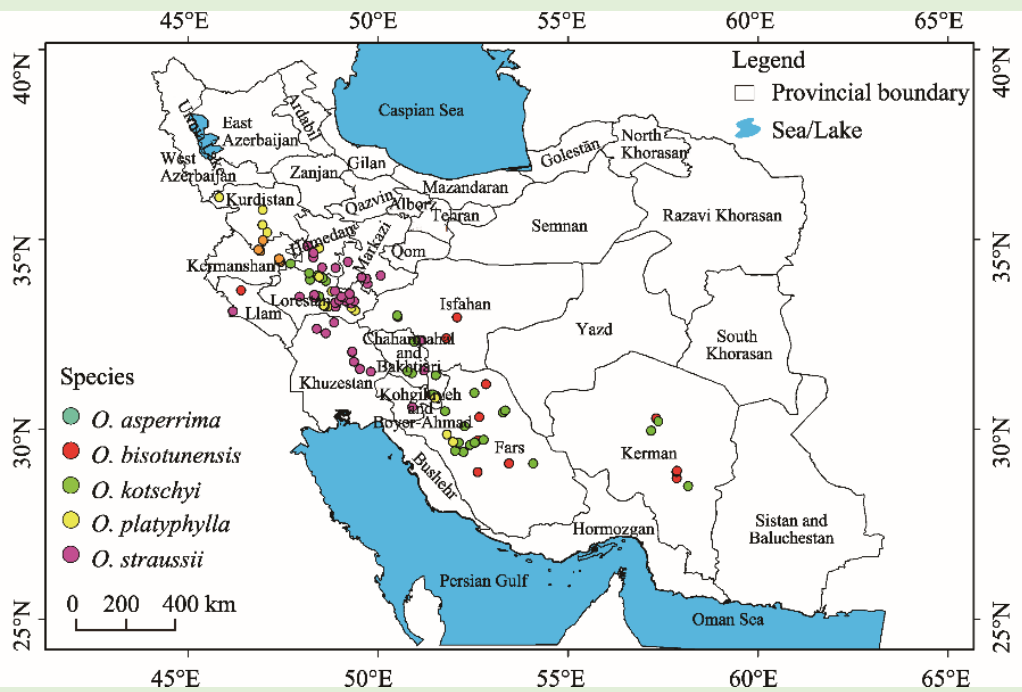

Fig. 2 Distribution map (presence data) of O. asperrima, O. bisotunensis, O. kotschyi, O. platyphylla, and O. straussii in Iran

\subsection{Selection of environmental variables}

In this study, according to expert opinion and the ecological need of the species, we initially used a total of 13 environmental variables related to the distribution of Onosma as follows: BIO1 (annual mean temperature), BIO5 (maximum temperature of warmest month), BIO6 (minimum temperature of coldest month), BIO7 (annual temperature range (BIO5-BIO6)), BIO12 (annual precipitation), aspect, elevation, slope, solar radiation per month, land use, silt content, soil organic carbon content, and depth of soil. Afterwards, collinearity among environmental variables was tested by Pearson's correlation coefficient $(r)$. If two variables were highly correlated $(r>|0.70|)$, one of them was excluded in order to avoid co-linearity (Elith et al., 2010). The source of selected variables after correlation test is available in Table 1 . To represent climate change influences, we used projected future climate variables for 2050 and 2080 with empirically downscaled bioclimatic data downloaded from the CCAFS website (Climate Change, Agriculture and Food Security; http://www.ccafs-climate.org), and the average of 16 General Circulation Models (GCMs) under optimistic (RCP2.6) and pessimistic (RCP8.5) greenhouse-gas emissions scenarios. The resolution of environmental variables used in the study was 30 arc-seconds (ca. $1 \mathrm{~km} \times 1 \mathrm{~km}$ ).

\subsection{Modeling process and evaluation}

MaxEnt model (Phillips et al., 2006) was utilized for modeling the current and future habitat suitability of species. MaxEnt (jar file v3.4.1) was utilized through the dismo package v1.1-4 (https://rspatial.org/raster/sdm/) in the R v3.2.3 programming environment (R Core Team, 2018). According to some previous studies (Bosso et al., 2013; Vasconcelos et al., 2014; Fois et al., 2018), we predominantly used the MaxEnt model when the data points included presence-only 
Table 1 Source of selected variables after correlation test and estimates of their permutation importance in maximum entropy (MaxEnt) modeling for the studied Onosma species

\begin{tabular}{|c|c|c|c|c|c|c|}
\hline \multirow[b]{2}{*}{ Source } & \multirow[b]{2}{*}{ Variable } & \multicolumn{5}{|c|}{ Permutation importance (\%) } \\
\hline & & $\begin{array}{c}O . \\
\text { asperrima } \\
\end{array}$ & $\begin{array}{c}O . \\
\text { bisotunensis }\end{array}$ & $\begin{array}{c}O . \\
\text { kotschyi }\end{array}$ & $\begin{array}{c}O . \\
\text { platyphylla }\end{array}$ & $\begin{array}{c}O . \\
\text { straussii }\end{array}$ \\
\hline \multirow{3}{*}{$\begin{array}{l}\text { Bioclimatic variables } \\
\text { (www.worldclim.org) }\end{array}$} & BIO6 & 1.8 & 0.1 & 1.6 & 5.4 & 4.5 \\
\hline & $\mathrm{BIO} 7$ & 0.3 & 37.7 & 7.0 & 24.2 & 32.5 \\
\hline & BIO12 & 11.9 & 34.9 & 7.6 & 1.7 & 28.4 \\
\hline \multirow{2}{*}{$\begin{array}{l}\text { Topographic variables } \\
\text { (www.worldgrids.org) }\end{array}$} & Aspect & 0.7 & 2.7 & 0.5 & 1.7 & 0.7 \\
\hline & Slope & 70.7 & 2.5 & 75.4 & 35.7 & 12.7 \\
\hline \multirow{2}{*}{$\begin{array}{c}\text { Edaphic variables (www.soilgrid.org; } \\
\text { www.isric.org) }\end{array}$} & Silt content & 4.2 & 0.9 & 7.5 & 23.1 & 12.0 \\
\hline & Depth of soil & 10.4 & 21.3 & 0.5 & 8.2 & 9.3 \\
\hline
\end{tabular}

Note: BIO6, minimum temperature of coldest month; BIO5, maximum temperature of warmest month; BIO7, annual temperature range; BIO12, annual precipitation. BIO7=BIO5-BIO6. Aspect and slope were all derived from elevation.

with a limited number of records. This is because the MaxEnt fits models with varying levels of complexity with respect to the amount of available data. Thus, for the species with few presence records, it fits simpler models (Elith et al., 2011). The models were evaluated using 10-fold cross-validation. In cross-validation, data were randomly divided into ten parts; nine parts were used for model fitting and the fitted model was then used to evaluate the holdout part (Valavi et al., 2019). For predicting the current and future suitability, a single MaxEnt model with full dataset was re-fitted.

We also considered permutation importance in order to define main environmental variables which have influenced the potential distributions of the studied species (Abdelaal et al., 2019). To assess the accuracy of the modeling results, we computed the area under the curve (AUC) of the receiver operating characteristic curve (Lobo et al., 2008). The AUC score is a powerful tool for measuring model performance because of its independence from threshold selection (Yi et al., 2016; Fois et al., 2018). The AUC shows the power of the model to discriminate presences from random background (Phillips et al., 2009) The AUC ranges between 0.000 and 1.000, with 0.500 showing a random prediction performance and 1.000 indicating a perfect discrimination. Values under 0.500 indicate models worse than random (Elith et al., 2006). The equal training sensitivity and specificity of MaxEnt output was considered as proper threshold for the model prediction (Liu et al., 2013).

\section{Results}

\subsection{Model performance and the key environmental factors influencing species distributions}

After the correlation test, we selected seven environmental variables for modeling (Table 1). The modeling outputs for the potential habitat suitability of $O$. asperrima, O. bisotunensis, $O$. kotschyi, $O$. platyphylla, and $O$. straussii showed a perfect predictive performance with AUC values higher than $0.800(0.823,0.973,0.922,0.943$, and 0.895 , respectively). Considering permutation importance, slope, BIO12, and depth of soil were the main environmental variables to have influenced the potential distribution of O. asperrima (Table 1). In this regard, BIO7, BIO12, and depth of soil were most important for O. bisotunensis. For O. kotschyi, most important variables were slope, BIO12, and silt content. For O. platyphylla, variables of slope, BIO7, and silt content were important; and finally for O. straussii, variables of BIO7, BIO12, and slope were important (Table 1). As can be further seen in Table 1, BIO6 and aspect proved less important than other variables for all species.

\subsection{Potential habitat suitability of the studied species in current and future conditions}

Species distribution maps showed that the potential suitable habitats of $O$. asperrima and $O$. kotschyi are currently located in some parts of the Kurdo-Zagrosian and Fars-Kerman 
phytogeographic sub-provinces in Lorestan, Chaharmahal and Bakhtiari, Kohgiluyeh and Boyer-Ahmad, Fars, and Kerman provinces (Figs. 3 and 4). The MaxEnt model predicted that the potential suitable habitats of $O$. bisotunensis lie in the northern parts of the Kurdo-Zagrosian phytogeographic zone in Kermanshah and Kurdistan provinces as well as in some parts of West Azarbaijan (Fig. 5). The suitable habitats of $O$. platyphylla are mainly located in the central Zagros (Kermanshah, Kurdistan, Lorestan, Chaharmahal and Bakhtiari, and Kohgiluyeh and Boyer-Ahmad) as well as in other parts of the Kurdo-Zagrosian phytogeographic sub-province (West Azarbaijan, Fars, and Kerman provinces) (Fig. 6).
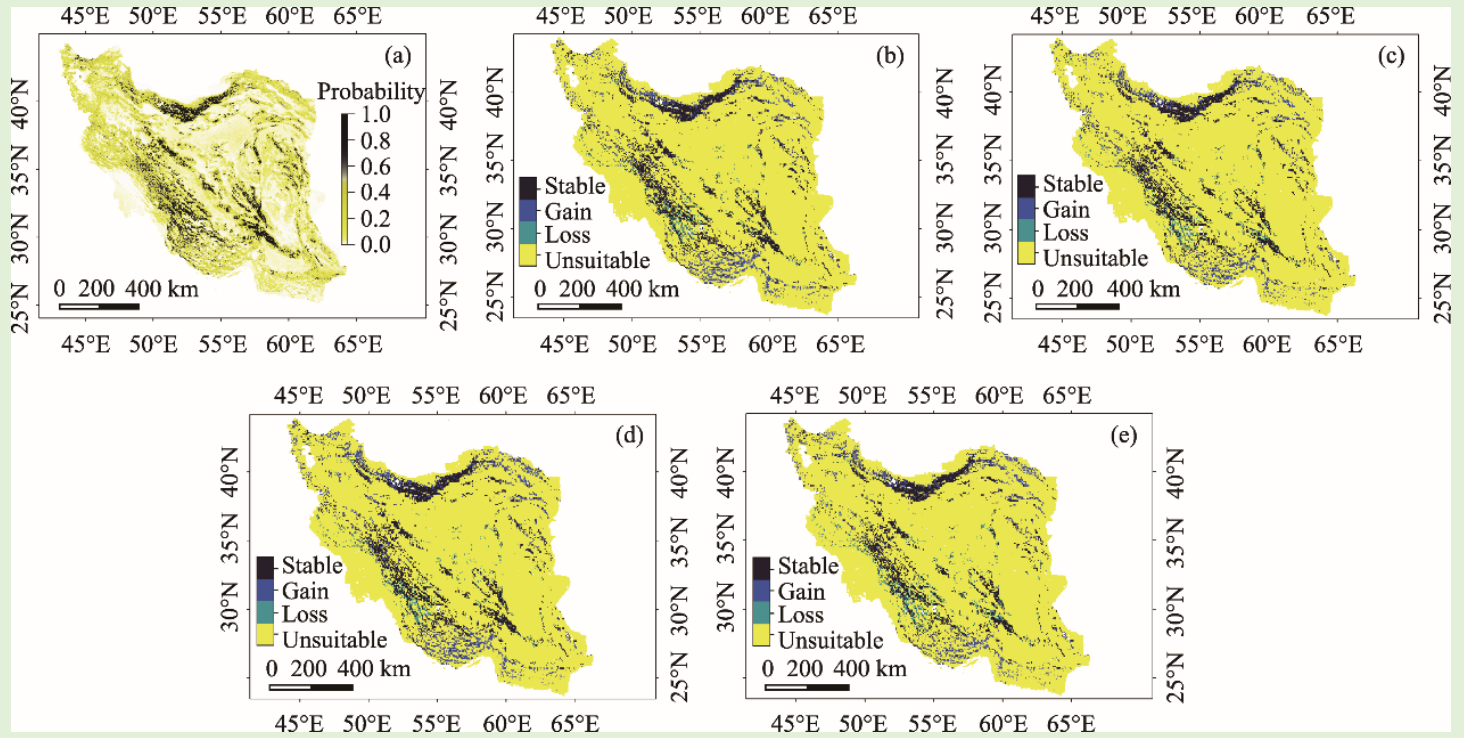

Fig. 3 Projection of potential distribution maps of $O$. asperrima currently and under climate change scenarios RCP2.6 and RCP8.5 in 2050 and 2080. (a), current prediction; (b), future prediction under RCP2.6 in 2050; (c), future prediction under RCP2.6 in 2080; (d), future prediction under RCP8.5 in 2050; (e), future prediction under RCP8.5 in 2080.
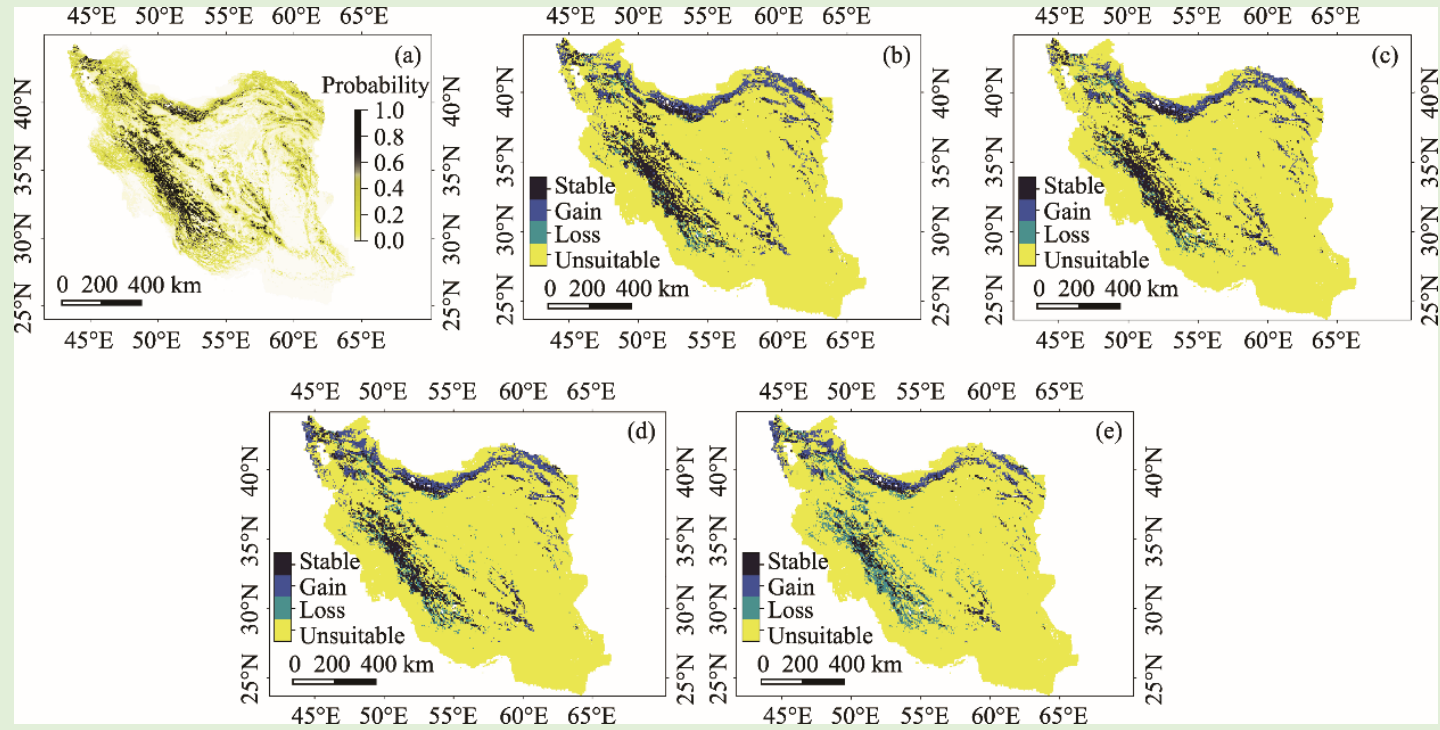

Fig. 4 Projection of potential distribution maps of $O$. kotschyi currently and under climate change scenarios RCP2.6 and RCP8.5 in 2050 and 2080. (a), current prediction; (b), future prediction under RCP2.6 in 2050; (c), future prediction under RCP2.6 in 2080; (d), future prediction under RCP8.5 in 2050; (e), future prediction under RCP8.5 in 2080. 

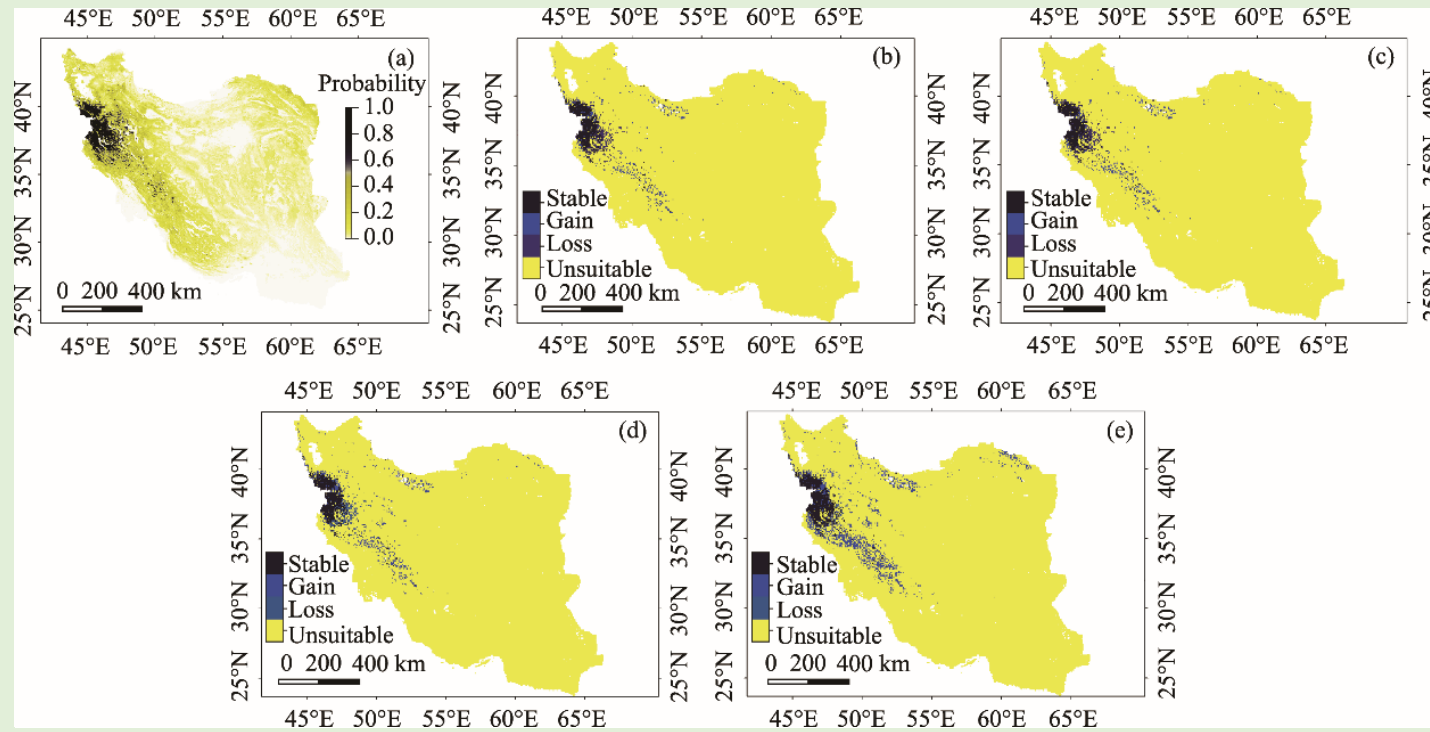

Fig. 5 Projection of potential distribution maps of $O$. bisotunensis currently and under climate change scenarios RCP2.6 and RCP8.5 in 2050 and 2080. (a), current prediction; (b), future prediction under RCP2.6 in 2050; (c), future prediction under RCP2.6 in 2080; (d), future prediction under RCP8.5 in 2050; (e), future prediction under RCP8.5 in 2080.
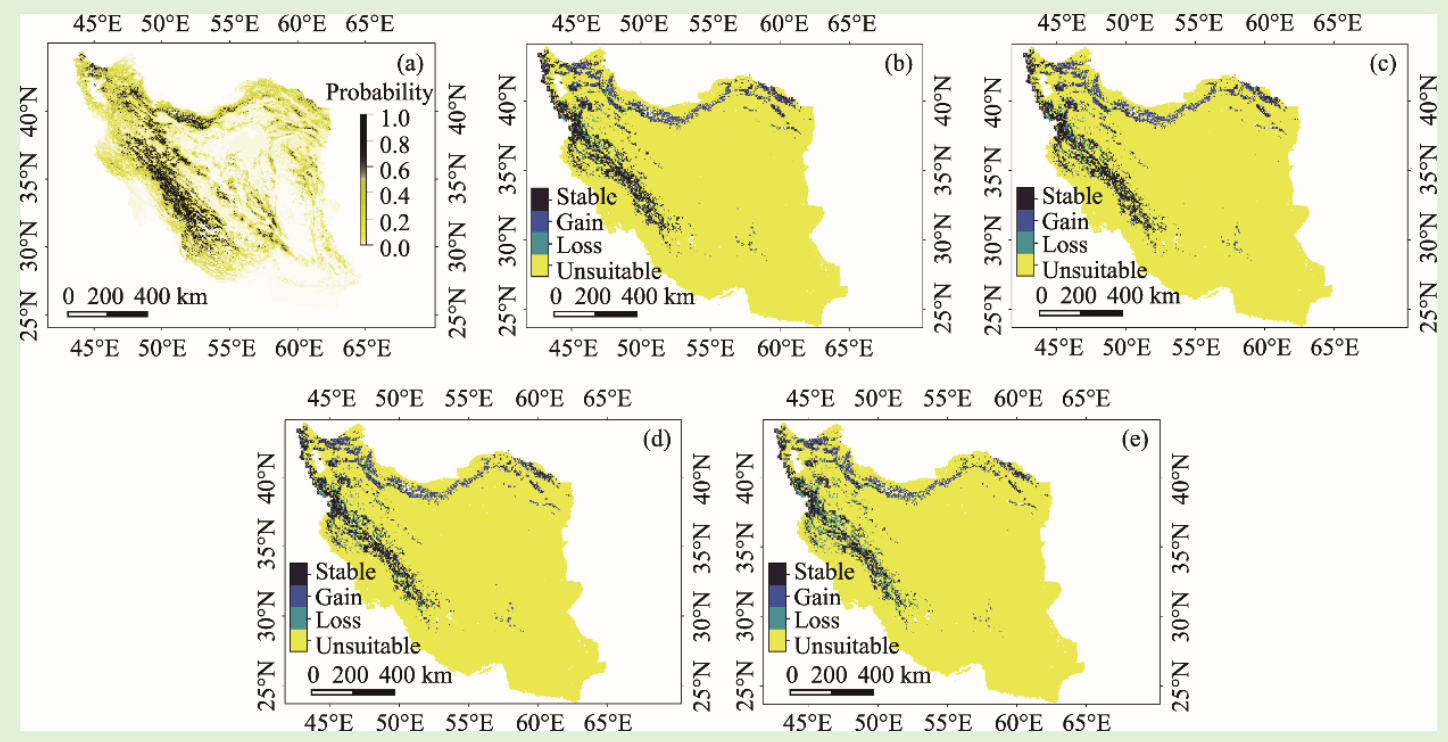

Fig. 6 Projection of potential distribution maps of $O$. platyphylla currently and under climate change scenarios RCP2.6 and RCP8.5 in 2050 and 2080. (a), current prediction; (b), future prediction under RCP2.6 in 2050; (c), future prediction under RCP2.6 in 2080; (d), future prediction under RCP8.5 in 2050; (e), future prediction under RCP8.5 in 2080.

The potential suitable habitats of $O$. straussii are located in the Kurdo-Zagrosian phytogeographic sub-province and some regions of the central phytogeographic sub-provinces in Kermanshah, Lorestan, Markazi, Hamedan, and Khuzestan provinces (Fig. 7). The projected climate maps under optimistic and pessimistic scenarios (RCP2.6 and RCP8.5, respectively) of 2050 and 2080 resulted in reductions and expansions as well as positive range changes for all species in comparison to their current predicted distributions (Figs. 3-7; Tables 2 and 3). Among all species, $O$. bisotunensis showed the most significant and highest increase under the pessimistic scenarios of 2050 and 2080. Among all, O. straussii exhibited the highest increase under the optimistic scenarios of 2050 and 2080. 

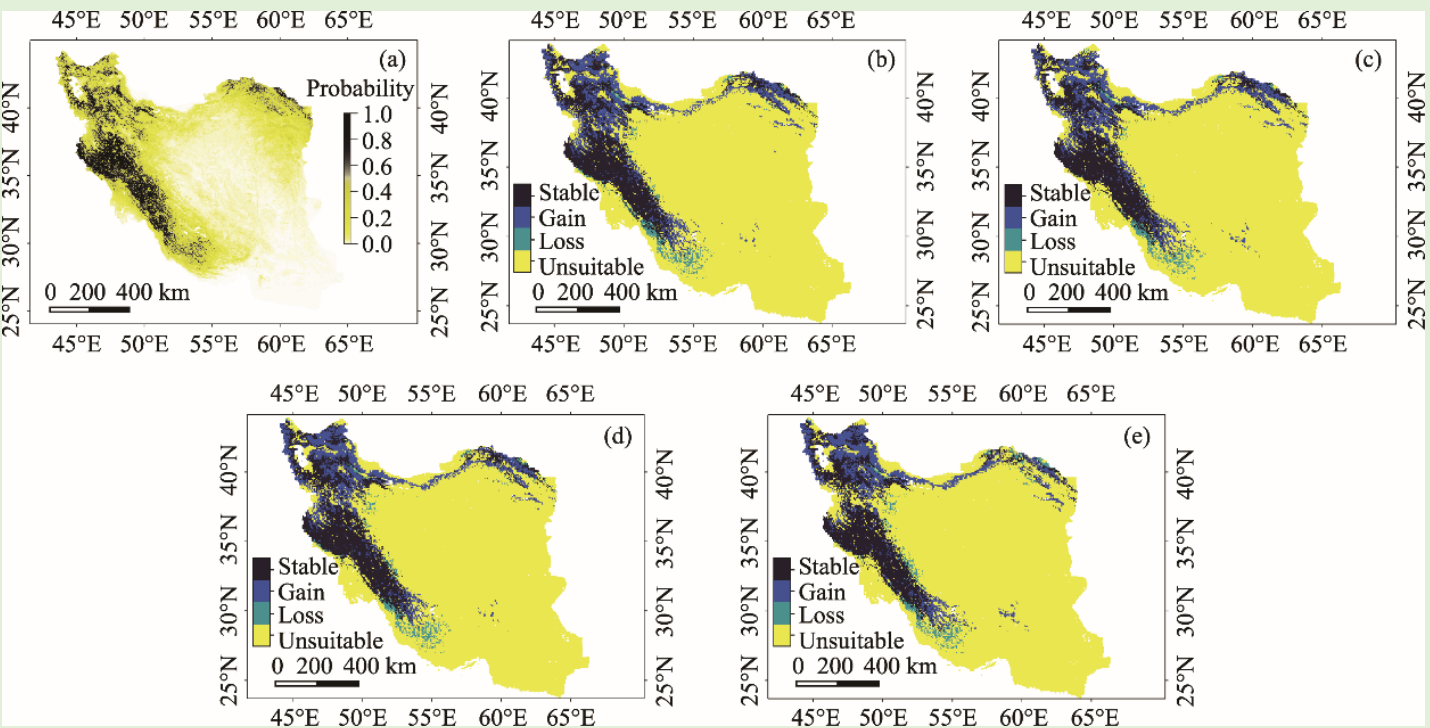

Fig. 7 Projection of potential distribution maps of $O$. straussii currently and under climate change scenarios RCP2.6 and RCP8.5 in 2050 and 2080. (a), current prediction; (b), future prediction under RCP2.6 in 2050; (c), future prediction under RCP2.6 in 2080; (d), future prediction under RCP8.5 in 2050; (e), future prediction under RCP8.5 in 2080.

Table 2 Percentages of gain, loss, and change in the distributions of the studied species under climate change scenario RCP2.6 in 2050 and 2080

\begin{tabular}{|c|c|c|c|c|c|c|}
\hline \multirow{3}{*}{ Species } & \multicolumn{6}{|c|}{ Climate change scenario RCP2.6 } \\
\hline & \multicolumn{3}{|c|}{2050} & \multicolumn{3}{|c|}{2080} \\
\hline & Gain (\%) & Loss (\%) & Change (\%) & Gain (\%) & Loss $(\%)$ & Change (\%) \\
\hline O. asperrima & 42.80 & 9.43 & 33.37 & 38.67 & 11.07 & 27.60 \\
\hline O. bisotunensis & 50.01 & 27.78 & 22.23 & 54.74 & 27.90 & 26.84 \\
\hline O. kotschyi & 42.47 & 15.05 & 27.42 & 38.87 & 18.02 & 20.86 \\
\hline O. platyphylla & 48.57 & 16.22 & 32.30 & 47.71 & 18.38 & 29.33 \\
\hline O. straussii & 64.37 & 14.71 & 49.66 & 65.38 & 14.13 & 51.76 \\
\hline
\end{tabular}

Note: Threshold was 0.369 for O. asperrima, 0.654 for O. bisotunensis, 0.349 for $O$. kotschyi, 0.398 for O. platyphylla, and 0.397 for $O$. straussii.

Table 3 Percentages of gain, loss, and change in the distributions of the studied species under climate change scenario RCP 8.5 in 2050 and 2080

\begin{tabular}{|c|c|c|c|c|c|c|}
\hline \multirow{3}{*}{ Species } & \multicolumn{6}{|c|}{ Climate change scenario RCP8.5 } \\
\hline & \multicolumn{3}{|c|}{2050} & \multicolumn{3}{|c|}{2080} \\
\hline & Gain (\%) & Loss $(\%)$ & Change (\%) & Gain (\%) & Loss (\%) & Change (\%) \\
\hline O. asperrima & 58.83 & 7.50 & 46.33 & 52.03 & 8.91 & 43.12 \\
\hline O. bisotunensis & 73.97 & 23.51 & 50.46 & 164.34 & 9.11 & 155.23 \\
\hline O. kotschyi & 51.16 & 11.78 & 39.38 & 49.01 & 13.03 & 35.98 \\
\hline O. platyphylla & 46.79 & 17.72 & 29.07 & 45.46 & 22.57 & 23.06 \\
\hline O. straussii & 65.17 & 14.52 & 51.20 & 69.65 & 14.58 & 55.07 \\
\hline
\end{tabular}

Note: Threshold was 0.369 for O. asperrima, 0.654 for $O$. bisotunensis, 0.349 for $O$. kotschyi, 0.398 for O. platyphylla, and 0.397 for $O$. straussii.

\section{Discussion}

This study has demonstrated the potential geographical distributions of five endemic species of the Onosma in Iran under both current and future climate scenarios. The current distribution patterns of these taxa are often concentrated in the western parts of the country. The Zagros 
Mountains are one of the most important centers of speciation in Iran, with a rich and diverse flora and fauna. These mountain ranges are located in the transitional zones between the Irano-Turanian and Mediterranean areas, which have created a variety of habitats and ecosystems for many plant species with a high degree of endemism (Zohary, 1973; Hedge and Wendelbo, 1978; Mehrabian, 2015; Mehrabian et al., 2020b). The phyto-geographical studies of this genus indicate that the western slopes of Zagros Mountains are one of the important plant areas and a priority for conservation of Onosma species in Iran (Mehrabian, 2015). Seventy-five percent of all endemic species of the genus including O. asperrima, O. bisotunensis, O. kotschyi, O. platyphylla, and $O$. straussii are distributed in the central and northern Zagros mountain ecosystem. Zagros is one of the most important biodiversity zones in the world and one of the most vital endemic centers of this genus (Mehrabian, 2015). Many endemic and crucial species of this genus are endangered in Zagros due to their limited distributions and the wide range of threats they face. Unfortunately, these ecosystems have been at risk of destruction for various reasons. Land conversion, overgrazing, and fire have reduced the number of valuable Zagrosian plant species in recent decades. In addition, several studies have shown the negative effects of climate change on the Zagros mountain ecosystem (Hosseini and Asghari, 2012; Valavi et al., 2018). Due to the fact that the O. asperrima, O. bisotunensis, O. kotschyi, O. platyphylla, and O. straussii species are endangered (EN) according to the IUCN Red List of Threatened Species (Mehrabian, 2015) and the suitable habitats of this species are located in the Zagros Mountains, their habitats must be protected accordingly.

The results obtained in the present study showed that BIO12, BIO7, silt content, slope, and depth of soil are generally key to the geographic distributions of the studied species. Climate is a dominant component in ecology and affects the growth of plants and their distribution patterns. Therefore, climate variables act as a natural selection factor in the formation of diverse vegetation (Adams, 2007). Several ecological studies (Mehrabian, 2015; Moradi et al., 2019) in different bioclimatic zones of Iran emphasize the importance of climate in the establishment of endemism, diversity, and genetic divergence in Onosma. For example, precipitation (BIO12) is actually a key eco-factor for the habitat suitability of most species in the present study. By affecting seed germination (Quevedo-Robledo, 2010), seedling growth and survival (Padilla and Pugnaire, 2007), and phenology (Mathias and Chesson, 2013), precipitation plays a determinant role in species richness, species distribution patterns, and diversification of plant species (Pausas and Austin, 2001; Yan et al., 2015). This environmental factor has a fundamental role in the potential distribution models of certain Iranian plant species including Astragalus caragana Fischer \& C. A. Meyer (Ardestani et al., 2015) and Daphne mucronata Royle (Abolmaali et al., 2018). Further, the temperature variable such as $\mathrm{BIO} 7$ is a main environmental factor influencing the spatial distributions of most species in this study.

The distributions of plant taxa also mainly depend on edaphic factors (silt content and depth of soil) and geomorphological factors (slope and aspect) (Hanson and Churchill, 1962; Guisan and Thuiller, 2005). The edaphic parameters, unlike climate variables, are not homogeneous across a landscape and can vary based on the type of parental materials (Anderson, 1988), geomorphologic situations (Ceddia et al., 2009), and land use (Mwanjalolo Jackson-Gilbert, 2015) from place to place. Therefore, they should always be considered in SDM studies (Velazco et al., 2017). Several studies (Mehrabian, 2015; Sayadi et al., 2017; Moradi et al., 2019) on the ecology of this genus in Iran emphasize the role of soil factors such as depth and silt content in the diversity and endemism of this genus. Geomorphology is also a main ecological factor influencing the distributions and diversity of vegetation and plant taxa in mountainous zones (Cantlon, 1953; Coblentz and Riitters, 2004). Accordingly, it controls spatial redistribution of sunlight, heat, water, and soil nutrients (Parker and Branner, 1982; Feng et al., 2011). Several studies on plant diversity in the Taihang Mountains of China ( $\mathrm{Li}$ and Zhang, 2006), species diversity of the forest communities in the southern Taihang Mountains of China (Ru et al., 2006), topographic factors on vegetation mosaics and tree diversity in the Chihuahuan Desert of North America (Poulos and Camp, 2010), and vegetation and plant species diversity in the southern 
slopes of Vitosha Mountain, Southeast Bulgaria (Dyakov and Nikolay, 2014), emphasize the importance of slope in species diversity and distribution patterns in plant taxa. In addition, Mehrabian (2015) and Moradi et al. (2019) have confirmed these results in the context of ecological studies on Onosma in Iran.

Species will have three responses to climate change: adapting to the new climate, migrating to a suitable habitat, and going extinct (Yousefi et al., 2020). Climate change will probably affect most species negatively but some may benefit if the amount of suitable habitat increases. Identifying winners and losers is becoming an important topic in climate change studies (Muths et al., 2017; Kafash et al., 2018; Yousefi et al., 2020). Having identified winners and losers it would be possible to manage each species according to their specific response to changes. In this study, we modelled the impacts of climate change on the spatial distributions of five endemic species under optimistic and pessimistic scenarios (RCP2.6 and RCP4.5, respectively) of 2050 and 2080. Our results showed that all species will respond similarly to changes. As a matter of fact, suitable habitat for all five species will increase in the future and these species will benefit from a change in climate, even though they are endemic and threatened. Our results are in line with previous studies which predicted range expansions (Kafash et al., 2016; Farashi and Erfani, 2018; Kafash et al., 2018) for different taxonomic groups in the country.

The studied plant species have shown acute adaptability to environmental changes. On the basis of the physiology, genetics, and ecological features of different taxa, climate change will have a variety of effects on their future distribution patterns. Onosma is centered mainly in xero-habitats, including rock and sandy soils as well as serpentine geological formations (Cecchi et al., 2011) in the mountainous habitats of the Irano-Turanian regions of Asia along with the Mediterranean region, especially in Iran and Turkey. All of the above ecological conditions indicate the high adaptability of this species to stressful environmental conditions, especially to hot, dry habitats. This was confirmed by numerous geo-botanical studies (Mehrabian, 2015; Moradi et al., 2019) that have been conducted in Iran. In addition, several endemic species of Onosma (e.g., O. straussii, O. kotschyi, O. bistounensis, O. mozaffariani, O. sheidai, O. chrysocaheta, $O$. sarvestanica, and others) grow in the xeric steppe habitats of Iran; Mehrabian (2015) has proven that they are well adapted to these stressful habitats. All of the above reasons reinforce the possibility of habitat expansion of these species under future climate change scenarios. Similarly, some ecological modeling on drought-friendly species such as Capparis spinosa L. (Ashraf et al., 2018), Ambrosia artemisiifolia L. (Adhikari et al., 2019), Ambrosia trifida L. (Adhikari et al., 2019), and Solanum carolinense L. (Adhikari et al. 2019) confirmed these results. Additionally, climate change can alter the competitive interactions and species composition within communities (Howden et al., 2003). Therefore, a reduction in the competition of its companion species can lead to the expansion of these resistant species. On the basis of field observations, Mehrabian (2015) revealed that O. strausii rapidly spreads due to reduced competition in degraded habitats.

\section{Conclusions}

In this study, we used the MaxEnt as a tool for determining the priorities of protecting certain endemic species of the genus Onosma in Iran. It seems that the use of this tool can be able to accurately predict the potential habitats of these taxa. According to the results of this study, the habitat area of these species will increase in the future. Therefore, it is essential to manage and conserve the projected areas for these species in the future.

For successful conservation of plants facing climate change, we recommend regular monitoring of all ecosystems in Iran. Plants can be used as indicators at environmental, community, population, and individual levels. Thus, we encourage regular monitoring of plants to detect how ecosystems are responding to changes. Observation can be done by investigating the presence, absence, richness, and composition of plants in defined monitoring stations. Through regular monitoring programs, the presence of new species or the absence of previously recorded species will be detectable. Moreover, it would be possible to track differences in species distribution, 
richness, and composition. Having this information can support conservation planning of plants dealing with climate change. Regardless of the modeling results, the long-term physiological dormancy of seeds and the small populations of some local endemic species, along with the above factors may increase the threat of extinction of these valuable endemic species. In addition, frequent wildfires and destruction of habitats have put the Zagrosian ecosystems at risk of being completely destroyed. The results of this study could justify ex situ conservation strategies such as gene banks, field gene banks, and in vitro conservation for these valuable species in Iran.

\section{Acknowledgements}

Our special thanks are given to Dr. Roozbeh VALAVI for his considerable support in the modeling section, Ms. Sadaf SAYADI for her assistance in collecting of data and running of models, and two anonymous reviewers for their many helpful comments. We also thank Mrs. Andrea GHANNADIAN for editing this article.

\section{References}

Abolmaali S M R, Tarkesh M, Bashari H. 2018. MaxEnt modeling for predicting suitable habitats and identifying the effects of climate change on a threatened species, Daphne mucronata, in central Iran. Ecological Informatics, 43: 16-123.

Abdelaal M, Fois M, Fenu G, et al. 2019. Using MaxEnt modeling to predict the potential distribution of the endemic plant Rosa arabica Crép. in Egypt. Ecological Informatics, 50: 68-75.

Adams J. 2007. Vegetation-Climate Interaction: How Vegetation Makes the Global Environment. Chichester: Springer-Praxis Ltd., 21-26.

Adams-Hosking C, McAlpine C A, Rhodes J R, et al. 2015. Prioritizing regions to conserve a specialist folivore: considering probability of occurrence, food resources, and climate change. Conservation Letters, 8(3): 162-170.

Adhikari P, Jeon J, Kim H W, et al. 2019. Potential impact of climate change on plant invasion in the Republic of Korea. Journal of Ecology and Environment, 43(4): 352-363.

Akhani H. 2006. Flora Iranica: facts and figures and a list of publications by K. H. Rechinger on Iran and adjacent areas. Rostaniha, 7(2): 19-61.

Alamgir M, Mukul S A, Turton S M. 2015. Modelling spatial distribution of critically endangered Asian elephant and hoolock gibbon in Bangladesh forest ecosystems under a changing climate. Applied Geography, 60: 10-19.

Amedie F A. 2013. Impacts of Climate Change on Plant Growth, Ecosystem Services, Biodiversity, and Potential Adaptation Measure. Gothenburg: University of Gothenburg, 1-34.

Anderson D W. 1988. The effect of parent material and soil development on nutrient cycling in temperate ecosystems. Biogeochemistry, 5(1): 71-97.

Aragón P, Rodríguez M A, Olalla-Tárraga M A, et al. 2010. Predicted impact of climate change on threatened terrestrial vertebrates in central Spain highlights differences between endotherms and ectotherms. Animal Conservation, 13(4): 363373.

Ardestani G E, Tarkesh M, Bassiri M, et al. 2015. Potential habitat modeling for reintroduction of three native plant species in central Iran. Journal of Arid Land, 7: 381-390.

Ashraf U, Chaudhry M N, Ahmad S J, et al. 2018. Impacts of climate change on Capparis spinosa L. based on ecological niche modeling. PeerJ, 6: e5792, https://doi.org/10.7717/peerj.5792.

Bellard C, Bertelsmeier C, Leadley P, et al. 2012. Impacts of climate change on the future of biodiversity. Ecology letters, 365377.

Bender I M A, Kissling W D, Böhning-Gaese K, et al. 2019. Projected impacts of climate change on functional diversity of frugivorous birds along a tropical elevational gradient. Scientific Reports, 9: 17708.

Bleyhl B, Sipko T, Trepet S, et al. 2015. Mapping seasonal European bison habitat in the Caucasus Mountains to identify potential reintroduction sites. Biological Conservation, 191: 83-92.

Bonn A, Rodrigues A S L, Gaston K J. 2002. Threatened and endemic species: are they good indicators of patterns of biodiversity on a national scale? Ecology Letters, 5(6): 733-741.

Bosso L, Di Febbraro M, Cristinzio G, et al. 2016. Shedding light on the effects of climate change on the potential distribution of Xylella fastidiosa in the Mediterranean basin. Biological Invasions, 18: 1759-1768.

Cantlon J E. 1953. Vegetation and microclimates on north and south slopes of Cushetunk Mountain, New Jersey. Ecological Monographs, 23(3): 241-270.

Cecchi L, Coppi A, Selvi F. 2011. Evolutionary dynamics of serpentine adaptation in Onosma (Boraginaceae) as revealed by 
ITS sequence data. Plant Systematics and Evolution, 297(3-4): 185-199.

Ceddia M B, Vieira S R, Villela A L O, et al. 2009. Topography and spatial variability of soil physical properties. Scientia Agricola, 66(3): 338-352.

Coblentz D, Riitters K H. 2004. Topographic controls on the regional-scale biodiversity of the south-western USA. Journal of Biogeography, 31(7): 1125-1138.

Dubuis A, Pottier J, Rion V, et al. 2011. Predicting spatial patterns of plant species richness: a comparison of direct macroecological and species stacking modelling approaches. Diversity and Distributions, 17(6): 1122-1131.

Dyakov N. 2014. Gradient analysis of vegetation on the south slope of Vitosha Mountain, Southwest Bulgaria. Applied Ecology and Environmental Research, 12(4): 1003-1025.

Elith J, Graham C, Anderson R, et al. 2006. Novel methods improve prediction of species' distributions from occurrence data. Ecography, 29(2): 129-151.

Elith J, Leathwick J R. 2007. Predicting species distributions from museum and herbarium records using multiresponse models fitted with multivariate adaptive regression splines. Diversity and Distributions, 13(3): 165-175.

Elith J, Leathwick J R. 2009. Species distribution models: ecological explanation and prediction across space and time. Annual Review of Ecology, Evolution, and Systematics, 40: 677-697.

Elith J, Kearney M, Phillips S. 2010. The art of modelling range-shifting species. Methods in Ecology and Evolution, 1(4): 330-342.

Elith J, Phillips S J, Hastie T, et al. 2011. A statistical explanation of MaxEnt for ecologists. Diversity and Distributions, 17(1): 43-57.

Farashi A, Erfani M. 2018. Modeling of habitat suitability of Asiatic black bear (Ursus thibetanus gedrosianus) in Iran in future. Acta Ecologica Sinica, 38(1): 9-14.

Feng Y, Ma K M, Zhang Y X, et al. 2011. Effects of slope position on species abundance distribution of Quercus wutaishanica community in Dongling Mountain of Beijing. Chinese Journal of Ecology, 30(10): 2137-2144. (in Chinese)

Fisher W B. 1968. "Physical Geography". In: Fisher W B. The Cambridge History of Iran. Cambridge: Cambridge University, 3-110.

Fois M, Cuena-Lombraña A, Fenu G, et al. 2018. Does a correlation exist between environmental suitability models and plant population parameters? An experimental approach to measure the influence of disturbances and environmental change. Ecological Indicators, 86: 1-8.

Garcia R A, Cabeza M, Rahbek C, et al. 2014. Multiple dimensions of climate change and their implications for biodiversity. Science, 344(6183): 1247579.

Graham C H, Ferrier S, Huettman F, et al. 2004. New developments in museum-based informatics and applications in biodiversity analysis. Trends in Ecology \& Evolution, 19(9): 497-503.

Groves C R, Jensen D B, Valutis L L, et al. 2002. Planning for biodiversity conservation: Putting conservation science into Practice. BioScience, 52(6): 499-512.

Guillera-Arroita G, Lahoz-Monfort J J, Elith J, et al. 2015. Is my species distribution model fit for purpose? Matching data and models to applications. Global Ecology and Biogeography, 24(3): 276-292.

Guisan A, Thuiller W. 2005. Predicting species distribution: Offering more than simple habitat models. Ecology Letters, 8(9): 993-1009.

Guisan A, Tingley R, Baumgartner J B, et al. 2013. Predicting species distributions for conservation decisions. Ecology Letters, 16(12): 1424-1435.

Hanson H C, Churchill E D. 1962. The Plant Community. New York: Reinhold Publishing Corp, 1-218.

He J. 2009. Complex of shikonin and $\beta$-cyclodextrins by using supercritical carbon dioxide. Journal of Inclusion Phenomena and Macrocyclic Chemistry, 63(3): 249-255.

Hedge I C, Wendelbo P. 1978. Patterns of distribution and endemism in Iran. Notes from the Royal Botanic Garden. Edinburgh, UK, 36: 441-464.

Homke S, Verges J, Emami H, et al. 2004. Magnetostratigraphy of Miocene-Pliocene Zagros foreland deposits in the front of the Push-e Kush Arc (Lurestan Province, Iran). Earth and Planetary Science Letters, 225(3-4): 397-410.

Hosseini A, Asghari S. 2012. Investigating the relation between climatic variables and the dying occurrence in Iranian oak. In: $3^{\text {rd }}$ National Conference on Combating Desertification and Sustainable Development of Iran Desert Wetlands (Relying on Meighan Desert Wetland). Islamic Azad University of Arak, Arak, Iran, 1-5.

Howden S M, Ash A J, Barlow E W R, et al. 2003. An overview of the adaptive capacity of the Australian agricultural sector to climate change-options, costs and benefits. Report to the Australian Greenhouse Office, Canberra.

Kafash A, Kaboli M, Köhler G, et al. 2016. Ensemble distribution modeling of the Mesopotamian spiny-tailed lizard (Saara 
loricata) in Iran: an insight into the impact of climate change. Turkish Journal of Zoology, 40(2): 262-271.

Kafash A, Ashrafi S, Ohler A, et al. 2018. Climate change produces winners and losers: differential responses of amphibians in mountain forests of the Near East. Global Ecology and Conservation, 16: e00471.

Kaky E, Gilbert F. 2016. Using species distribution models to assess the importance of Egypt's protected areas for the conservation of medicinal plants. Journal of Arid Environments, 135: 140-146.

Khanum R, Mumtaz A S, Kumar S. 2013. Predicting impacts of climate change on medicinal asclepiads of Pakistan using MaxEnt modeling. Acta Oecologica, 49: 23-31.

Khatamsaz M. 2002. Boraginaceae. Flora of Iran 39. Tehran: Research Institute of Forests and Rangelands, 114-168. (in Persian)

Kujala H, Moilanen A, Araujo M B, et al. 2013. Conservation planning with uncertain climate change projections. PLoS ONE, 8(2): e5331.

Legault A, Theuerkauf J, Chartendrault V, et al. 2013. Using ecological niche models to infer the distribution and population size of parakeets in New Caledonia. Biological Conservation, 167: 149-160.

Li J L, Zhang J D. 2006. Plant species diversity in the middle part of the Taihang Mountain. Journal of Applied and Environmental Biology, 12: 766-771. (in Chinese)

Liu C, White M, Newell G. 2013. Selecting thresholds for the prediction of species occurrence with presence-only data. Journal of Biogeography, 40(4): 778-789.

Liu G L, Pang Y J, Shen H G, et al. 2010. Expression analysis of shikonin-biosynthetic genes in response to M9 medium and light in Lithospermum erythrorhizon cell cultures. Plant Cell Tissue and Organ Culture, 101(2): 135-142.

Loarie S R, Carter B E, Hayhoe K, et al. 2008. Climate change and the future of California's endemic flora. PLoS ONE, 3(6): e2502.

Lobo J M, Jiménez-Valverde A, Real R. 2008. AUC: A misleading measure of the performance of predictive distribution models. Global Ecology and Biogeography, 17(2): 145-151.

Luo Z, Jiang Z, Tang S. 2015. Impacts of climate change on distributions and diversity of ungulates on the Tibetan Plateau. Ecological Applications, 25(1): 24-38.

Margules C R, Pressey R L. 2000. Systematic conservation planning. Nature, 405: 243-253.

Mathias A, Chesson P. 2013. Coexistence and evolutionary dynamics mediated by seasonal environmental variation in annual plant communities. Theoretical Population Biology, 84(1): 56-71.

Mazangi A, Ejtehadi H, Mirshamsi O, et al. 2016. Effects of climate change on the distribution of endemic Ferula xylorhachis Rech.f. (Apiaceae: Scandiceae) in Iran: predictions from ecological niche models. Russian Journal of Ecology, 47(4): 349354.

Mehrabian A R. 2015. Distribution patterns and diversity of Onosma in Iran: with emphasis on endemism conservation and distribution pattern in SW Asia. Rostaniha, 16(1): 36-60. (in Persian)

Mehrabian A R, Amini R M. 2018. Onosma moussavi sp. nov (Boraginaceae) from Zagros Mountain (s) Iran. Feddes Repertorium, 129(4): 304-311.

Mehrabian A R, Khajoei Nasab F, Fraser-Jenkins C R, et al. 2020a. Distribution patterns and priorities for conservation of Iranian pteridophytes. Fern Gazetee, 21(4): 141-160.

Mehrabian A R, Sayadi S, Majidi K M, et al. 2020b. Priorities for conservation of Iranian endemic trees and shrubs. Asia-Pacific Journal of Biodiversity, 13(2): 295-305.

Moradi Z H, Mehrabian A R, Naghizadeh S, et al. 2019. Distribution patterns, diversity and conservation priorities of Onosma L. (Boraginaceae Juss.) in some sections of the northwestern geomorphologic unit of Iran. Environmental Sciences, 17(1): 73-94. (In Persian)

Muths E, Chambert T, Schmidt B R, et al. 2017. Heterogeneous responses of temperate-zone amphibian populations to climate change complicates conservation planning. Scientific Reports, 7(1): 17102.

Mwanjalolo Jackson-Gilbert M, Makooma M T, Rao K P C, et al. 2015. Soil fertility in relation to landscape position and land use/cover types: a case study of the Lake Kivu Pilot learning site. Advances in Agriculture, 2015: 752936, doi: $10.1155 / 2015 / 752936$.

Noroozi J, Moser D, Essl F. 2016. Diversity, distribution, ecology and description rates of alpine endemic plant species from Iranian mountains. Alpine Botany, 126(1): 1-9.

Noroozi J, Talebi A, Doostmohammadi M, et al. 2018. Hotspots within a global biodiversity hotspot - areas of endemism are associated with high mountain ranges. Scientific Reports, 8(1): 10345.

Noula E, Samanidou V F, Assimopoulou A N, et al. 2010. Solid-phase extraction for purification of alkannin/shikonin samples and isolation of monomeric and dimeric fractions. Analytical and Bioanalytical Chemistry, 397(6): 2221-2232. 
Padilla F M, Pugnaire F I. 2007. Rooting depth and soil moisture control Mediterranean woody seedling survival during drought. Functional Ecology, 21(3): 489-495.

Parker A J, Branner J C. 1982. The topographic relative moisture index: an approach to soil-moisture assessment in mountain terrain. Physical Geography, 3(2): 160-168.

Parmesan C. 2006. Ecological and evolutionary responses to recent climate change. Annual Review of Ecology, Evolution and Systematics, 37(1): 637-669.

Pausas J G, Austin M P. 2001. Patterns of plant species richness in relation to different environments: An appraisal. Journal of Vegetation Science, 12(2): 153-166.

Peñuelas J, Sardans J, Estiarte M, et al. 2013. Evidence of current impact of climate change on life: a walk from genes to the biosphere. Global Change Biology, 19(8): 2303-2338.

Pereira H M, Leadley P W, Proença V, et al. 2010. Scenarios for global biodiversity in the $21^{\text {st }}$ century, Science, 330(6010): 1496-1501.

Peterson A T, Soberón J. 2012. Species distribution modeling and ecological niche modeling: Getting the concepts right. Natureza \& Conservação, 10(2): 102-107.

Phillips S J, Anderson R P, Schapire R E. 2006. Maximum entropy modeling of species geographic distributions. Ecological Modeling, 190(3-4): 231-259.

Phillips S J, Dudík M, Elith J, et al. 2009. Sample selection bias and presence-only distribution models: implications for background and pseudo-absence data. Ecological Applications, 19(1): 181-197.

Poulos H M, Camp A E. 2010. Topographic influences on vegetation mosaics and tree diversity in the Chihuahuan Desert Borderlands. Ecology, 91(4): 1140-1151.

Quevedo-Robledo L, Pucheta E, Ribas-Fernández Y. 2010. Influences of interyear rainfall variability and microhabitat on the germinable seed bank of annual plants in a sandy Monte Desert. Journal of Arid Environments, 74(2): 167-172.

R Core Team, 2018. R: A Language and Environment for Statistical Computing. R Foundation for Statistical Computing, Vienna, Austria. [2019-05-21]. http://www.R-project.org/.

Riedl H. 1967. Boraginaceae. Flora Iranica 48. Graz: Akademische Druck-u Verlagsanstalt, 169-212.

Rivas-Martínez S, Sánchez-Mata D, Costa M. 1997. Syntaxonomical synopsis of the potential natural plant communities of North America, I. Itinera Geobotanica, 10: 5-148.

Rivas-Martínez S, Sánchez-Mata D, Costa M. 1999. Boreal and western temperate forest vegetation (syntaxonomical synopsis of the potential natural plant communities of North America, II). Itinera Geobotanica, 12: 3-311.

Rödder D, Weinsheimer F. 2009. Will future anthropogenic climate change increase the potential distribution of the alien invasive Cuban treefrog (Anura: Hylidae)? Journal of Natural History, 43(19-20): 1207-1217.

Roshan G H, Azizi G, Mohammadi H. 2011. Simulation of temperature changes in Iran under the atmosphere carbon dioxide duplication condition. Journal of Environmental Health Science \& Engineering, 8(2): 141-146.

Ru W M, Zhang G P, Zhang J D, et al. 2006. Species diversity of forest communities in southern Taihang Mountains, Shanxi. Acta Botanica Boreali-Occidentalia Sinica, 26(5): 1036-1042. (in Chinese)

Rubidge E M, Monahan W B, Parra J L, et al. 2011. The role of climate, habitat, and species co-occurrence as drivers of change in small mammal distributions over the past century. Global Change Biology, 17(2): 696-708.

Sala O E, Chapin F S, Armesto J J, et al. 2000. Global biodiversity scenarios for the year 2100. Science, 287(5459): 1770-1774.

Sayadi S, Mehrabian A R, Nikjoyan M J. 2017. Some notes on taxonomy and diversity of Onosma with emphasis on important evidence and complex groups in Flora Iranica. Rostaniha, 18(1): 50-58.

Sayadi S, Mehrabian A R. 2016. Diversity and distribution patterns of Solanaceae in Iran: Implications for conservation and habitat management with emphasis on endemism and diversity in SW Asia. Rostaniha, 17(2): 136-160.

Sen S, Gode A, Ramanujam S, et al. 2016. Modeling the impact of climate change on wild Piper nigrum (Black Pepper) in Western Ghats, India using ecological niche models. Journal of Plant Research, 129(6): 1033-1040.

Soberón J, Peterson A T. 2005. Interpretation of models of fundamental ecological niches and species' distributional areas. Biodiversity Informatics, 2: 1-10.

Sut S, Pavela R, Kolarčik V, et al. 2017. Identification of Onosma visianii roots extract and purified shikonin derivatives as potential acaricidal agents against Tetranychus urticae. Molecules, 27(6): 1002.

Tallis H, Kareiva P, Marvier M, et al. 2008. An ecosystem services framework to support both practical conservation and economic development. Proceedings of the National Academy of Sciences of the United States of America, 105(28): 94579464.

Thiers B. 2019. Index herbariorum: A global directory of public herbaria and associated staff. New York Botanical Garden's Virtual Herbarium. [2020-04-15]. http://sweetgum.nybg.org/ih. 
Ulrey C, Quintana-Ascencio P F, Kauffman G, et al. 2016. Life at the top: Long-term demography, microclimatic refugia, and responses to climate change for a high-elevation southern Appalachian endemic plant. Biological Conservation, 200 : 80-92.

Valavi R, Shafizadeh-Moghadam H, Matkan A A, et al. 2018. Modelling climate change effects on Zagros forests in Iran using individual and ensemble forecasting approaches. Theoretical and Applied Climatology, 137: 1015-1025.

Valavi R, Elith J, Lahoz-Monfort J J, et al. 2019. An r package for generating spatially or environmentally separated folds for $k$-fold cross-validation of species distribution models. Methods in Ecology and Evolution, 10(2): 225-232.

Vasconcelos T S, Nascimento B T M. 2014. The utility of open-access biodiversity information in representing anurans in the Brazilian Atlantic Forest and Cerrado. Phyllomedusa, 13(1): 51-58.

Velazco S J E, Galvão F, Villalobos F, et al. 2017. Using worldwide edaphic data to model plant species niches: An assessment at a continental extent. PLoS ONE, 12(10): e0186025.

Warren R, VanDerWal J, Price J, et al. 2013. Quantifying the benefit of early climate change mitigation in avoiding biodiversity loss. Nature Climate Change, 3(7): 678-682.

Yan H, Liang C, Li Z, et al. 2015. Impact of precipitation patterns on biomass and species richness of annuals in a dry steppe. PLoS ONE, 10(4): e0125300.

Yi Y, Cheng X Y, Yang Z, et al. 2016. MaxEnt modeling for predicting the potential distribution of endangered medicinal plant (H riparia Lour) in Yunnan, China. Ecological Engineering, 92: 260-269.

Yousefi M, Jouladeh-Rodbar A, Kafash A. 2020. Using endemic freshwater fishes as proxies of their ecosystems to identify high priority rivers for conservation under climate change. Ecological Indicators, 112: 106137.

Zahran M A. 2010. Climate-Vegetation: Afro-Asian Mediterranean and Red Sea Coastal Lands. New York: Springer Science \& Business Media, 324.

Zohary M. 1973. Geobotanical Foundations of the Middle East (Vol. 2). Stuttgart: Gustav Fisher Verlag, 738. 